\title{
Smoking Cessation: Problems and Opportunities and Future Perspectives
}

\author{
Karl Fagerström \\ Smoker's Information Centre, Helsingborg, Sweden \\ Ernest Groman \\ Institute of Social Medicine, Centre of Public Health, Medical University of Vienna and Nicotine Institute, Austria
}

Carlos Andres Jimenez Ruiz

Unidad Especializada en Tabaquismo, Communidad de Madrid, Spain

There are a good number of scientific journals to which you could send your 'scientific' papers on tobacco and nicotine. Some are devoted to only tobacco and nicotine and others to addictions in general. These journals reflect the great advances that have been made in understanding everything from the molecular level of nicotinic receptors over the health hazards revealed by epidemiology to the social and policy implications of various actions. Those advances have also increased awareness and the need for helping smokers to quit. Some 20 to 30 years ago there were not many countries that had specialised smokers clinics and few health care practices were interested in offering smokers treatment. That has changed. Today, smoking cessation counsellors, full- or part-time, is a profession in sharp increase. For example, just to mention two countries, in France and the United Kingdom smoking cessation services have been mandated by regulation.

For all of us involved in everyday cessation services there is a great need for journals with a more clinical interest in smoking cessation. The scientific journals have been very helpful but on the clinical level not everything can be evaluated in a rigours scientific way. For example, there is a need for clinicians to share tips, experience and information that they are gathering that cannot always be dressed in the proper scientific attire. Sometimes such knowledge can be seen as hypothesis-generating that later can be subjected to rigorous experimental studies. The problems most of us share are the difficulties in motivating smokers to comply with effective treatment regimes, for example, with nicotine replacement. We might all have different ways to increase compliance among our patients. An example of a good clinical story that I hope we can see many of in the journal is to compare stopping smoking with learning to swim, maybe in the 'swimming pool of life'. Nicotine replacement therapy (NRT) are the floats that keep their head above water while they learn to swim, then, when they eventually take the floats away they can swim and don't sink and are not going to be dependent on NRT for the rest of their lives. This story we actually learned from the editor-in-chief of this journal.

\section{How Is Smoking Cessation Going to Look in the Future?}

When the senior author started to treat smokers, some 30 years ago, they were fairly representative of the general population in most respects. Today, when the prevalence has been halved in some countries - for example, Sweden - the smokers seeking treatment are very different. Some have given up with help of the information provided, the social pressure, price increases and smoking bans. The remaining smokers might have had 'good reasons' to ignore this pressure, therefore they often present with comorbidity to the extent warranting a full diagnosis, and for others, a more subclinical nature. Offering encouragement in the form of advice to eat carrots and drink water when the urge sets in is no longer working, if it ever has. Today, counsellors need professional and state-of-the-art training in order to correctly assess and address the problem of tobacco dependence. Such knowledge may involve insights into common comorbidity conditions and use of more intensive behavioural and pharmacological treatments.

There is an agreement that tobacco smoking can be very addictive. Sometimes we say it is actually as, or even more, addictive than alcohol, heroin and cocaine. Seldom are the consequences drawn. Few clinicians treating alcoholics or heroin addicts would ask their patients to set a

Address for correspondence: Karl Fagerström, Smoker's Clinic, Berga Alle 1, Helsingborg 25452, Sweden. E-mail: Karl.fagerström@swipnet.se 
quit date when they quit abruptly and for life. When the correct consequences are realised, treating tobacco dependence will most likely be very different in the future. The treatment objectives and procedures used in the management of tobacco dependence will be more similar to those used with other addictions. Currently there is only one objective - complete abstinence - reached by abrupt quitting. Even without purposefully changing this objective we are starting to see a gradual sliding into reduced smoking before quitting. Three out of three studies that have tested use of NRT some weeks before quitting have shown improved compliance and efficacy (Herrera \& Fagerström, 1995; Schurmanns, Diacon, van Biljon, \& Bolliger, 2004; Rose, Behm, Westman, \& Kukvich, 2006) and such use is gradually being adopted. With bupropion and varenicline smokers start active treatment a week before quitting and often the smokers cut down on their smoking. The nicotine vaccines, if they reach the market, will take several weeks, if not months, before they are effective. No doubt reduction before quitting will be more common. Recently, regulatory authorities have approved Reduction to Quit for NR products, as it seems to be a method that is of interest to smokers not interested in quitting abruptly. Smokers who can reduce their smoking by at least $50 \%$ and maintain this reduction for at least 4 months increase their chances of giving up at 12-month follow-up (Fagerström, 2005). Sometimes when smokers say they are not interested in quitting it can just be a reflection of inability to quit abruptly.

It is, however, likely that we may have to offer other objectives too, if we want to help more smokers from suffering the harmful effects of tobacco smoking. To be realistic, there are smokers living such poor and miserable lives that they do not want to subject themselves to additional, at least short-term, misery for an investment to bear full fruit in health status toward their retirement age. Such smokers can still be well-adjusted people in our society, but more often they are found among prisoners, addicts, homeless and mentally ill people.

Smoking cessation may have to change its name to 'treatment of tobacco dependence' as cessation will not be the only objective. It could be complemented with reduced risk, harm and dependence by reducing intake of smoke, using less harmful tobacco products such as smoke-free tobacco, or partial or full replacement with NR products. It could also be positive to transfer daily smokers into occasional smokers with the help of any of the above-mentioned methods.

\section{Challenges}

With most other medical and social conditions there is a pressure on the health care system and politicians to provide adequate up to date services. Often the immediate stakeholders form their own patient organisations to care for their interests. This is not the situation with smoking. It looks as though smokers are reluctant to form a consumer or patient organisation, whether it is for claiming the right to less harmful products or help in giving up smoking.

Another characteristic with the treatment of tobacco dependence is that there is no one speciality/profession that owes, or is responsible for providing, information, training and treatment. Health professionals, to a large extent, lack knowledge about smoking cessation. Pregraduate training is scarce in most universities and postgraduate courses do not have enough accreditation to call for the attention of physicians and other health professionals. The recruitment of people into the area is therefore somewhat different and sometimes problematic. People that feel the need to be active in the area are selfselected and often filled with the strongest possible passion to fight against smoking, which sometimes makes them not the most diplomatic and easy to work with.

Two other related problems are the minimal acceptance that tobacco-dependence treatment therapists get from other colleagues in the medical and paramedical system. There is also very little of a carrier opportunity in treating smokers professionally, which makes the recruitment of the best people more difficult.

Anyway, what is referred to as smoking cessation is an area in rapid growth. There is certainly a need for a good journal where we can submit our work and learn from others to keep up with the increasing demands. There is hardly no one on earth that have treated more smokers than the editor-in-chief, Renee Bittoun, so the journal is under the best leadership and we want to wish it the very best.

\section{References}

Herrera, N., \& Fagerström, K.O. (1995). Nicotine gum, 2 and 4 $\mathrm{mg}$, according to nicotine dependence. Chest, 108, $447-451$.

Schurmanns, M.M., Diacon, A.H., van Biljon, X., \& Bolliger, C.T. (2004). Effect of pre-treatment with nicotine patch on withdrawal symptoms and abstinence rates in smokers subsequently quitting with the nicotine patch. Addiction, 99, 634-640.

Rose, J.E., Behm, F.M., Westman, E.C., \& Kukvich, P. (2006). Precessation treatment with nicotine patch facilitates smoking cessation. Nicotine Tobacco Research, 8, 89-101.

Fagerström, K.O. (2005). Can reduced smoking be a way for smokers not interested in quitting to actually quit? Respiration, 72, 216-220. 